\title{
SOBRE A ESTRUTURAÇÃO DE REDES SOCIAIS EM ASSOCIAÇÕES VOLUNTÁRIAS: ESTUDO EMPÍRICO DE ORGANIZAÇÕES NÃO-GOVERNAMENTAIS DA CIDADE DO RECIFE
}

\author{
Breno Augusto Souto Maior Fontes \\ Klaus Eichner
}

\begin{abstract}
Resumo. Este artigo tem por objetivo investigar os processos de estruturação das redes sociais em associações voluntárias, a partir de estudo empírico realizado em ONGs da cidade do Recife. Esta perspectiva de análise - o estudo do Terceiro Setor a partir da estruturação de seus atores em redes sociais - é bastante inovadora e permite alguns "insights" esclarecedores sobre o funcionamento das ONGs. Em primeiro lugar, a capacidade de uma ONG em mobilizar recursos para o seu funcionamento não é função exclusiva da relevância de sua missão. O sucesso de seu empreendimento depende da disponibilização dos recursos junto a diversos campos institucionais (governo, igreja, sociedade civil, cooperação internacional, etc.) e sua capacidade relativa pode ser medida comparativamente a outras ONGS a partir do desenho de suas redes sociais, que possibilita confrontar o montante de capital social disponível. Em segundo lugar, a estruturação das redes associativas permite verificar a dimensão dos vínculos institucionais, e como estes vínculos são mais ou menos importantes na determinação da agenda da ONG em questão. E se há um conflito (e em até que nível) nesta influência na determinação a partir de sua inserção institucional com a sua missão original. Os dados analisados provêm de pesquisa empírica realizada junto a 45 ONGs que atuam na cidade do Recife, entrevistadas a partir de amostra de bola de neve (snowball). Os
\end{abstract}

Breno Augusto Souto Maior Fontes é Professor do Programa de Pós-Graduação em Sociologia da Universidade de Federal de Pernambuco.

Klaus Eichner é Professor do Instituto de Sociologia da Universidade de Hamburgo. 
dados foram tratados estatisticamente a partir dos softwares SPSS e UNICET (este específico para processamento de informações sobre redes sociais).

Palavras-chave: $\mathrm{ONG}$, redes sociais, Recife (PE), mobilização de recursos.

\section{Introdução}

Este artigo tem por objetivo investigar os processos de estruturação das redes sociais em associações voluntárias, a partir de estudo empírico realizado em ONGs da cidade do Recife. Esta perspectiva de análise o estudo do Terceiro Setor a partir da estruturação de seus atores em redes sociais - é bastante inovadora e permite alguns insights esclarecedores sobre o funcionamento das Organizações NãoGovernamentais (ONGs). Em primeiro lugar, a capacidade de uma ONGs em mobilizar recursos para o seu funcionamento não é função exclusiva da relevância sua missão. O sucesso de seu empreendimento depende da disponibilização dos recursos junto a diversos campos institucionais (governo, igreja, sociedade civil, cooperação internacional, etc.) e sua capacidade relativa pode ser medida comparativamente a outras ONGs a partir do desenho de suas redes sociais, o que possibilita confrontar o montante de capital social disponível. Em segundo lugar, a estruturação das redes associativas permite verificar a dimensão dos vínculos institucionais, e como estes vínculos são mais ou menos importantes na determinação da agenda da ONG em questão. E se há um conflito (e em até que nível) nesta influência na determinação a partir de sua inserção institucional com a sua missão original.

Os dados analisados provém de pesquisa empírica realizada na cidade do Recife, onde foram entrevistadas, a partir de amostra de bola de neve (snowball) ${ }^{1}$ é 40 ONGs que atuam nessa cidade. A escolha deste tipo de amostra para extração dos dados, além de estratégica para a mensuração de alguns indicadores de redes, também se justifica pela escassez e informações desencontradas sobre a realidade das ONGs no Brasil. Temos, com efeito, vários bancos de dados que não são concordantes no que diz respeito aos registros de ONGs. Isto nos leva a uma dificuldade adicional: a de registrar com um nível mínimo de 
acurácia o nosso universo de pesquisa. De qualquer forma, mesmo que tivéssemos informações completas sobre o nosso universo de pesquisa, não seria possível aplicar uma amostra probabilística, visto que para trabalharmos com os dados utilizando-se da metodologia de redes, teríamos de ter informações sobre a totalidade dos laços sociais (o que é possível somente entrevistando todas as ONGs). A amostra "bola de neve" permite-nos contornar esta dificuldade, porque a amostra se encerra quando o índice de repetições é muito alto, o que significa que a rede já está quase toda representada. ${ }^{2}$ Desta forma, poderemos extrair alguns indicadores de redes como densidade, multiplexidade, outdegree e indegree, etc. ${ }^{3}$

Os dados foram tratados estatisticamente a partir dos softwares SPSS e UNICET (este específico para processamento de informações sobre redes sociais). O questionário aplicado é composto, em sua maior parte, de perguntas fechadas, divididas em informações sobre o entrevistado e informações sobre as redes sociais da ONG à qual o entrevistado está filiado institucionalmente. As informações sobre redes partem de uma matriz de instituições indicadas (até nove por entrevistado, com um total máximo de 360 instituições) com as quais as ONGs que compõem a rede em questão se relacionam. Estas redes podem ser tanto de natureza interna (redes de ONGs), como de natureza mais ampla (redes de instituições diversas, que vão desde organizações de cooperação internacional até órgãos do governo).

Este artigo está estruturado em dois blocos distintos:

a) uma revisão da literatura, onde apresentaremos questões pertinentes às nossas hipóteses, que dizem respeito basicamente a discussões sobre ONGs, enquanto atores da sociedade civil e que vêm tomando cada vez maior visibilidade recentemente; da introdução da discussão sobre redes sociais enquanto instrumento importante para a compreensão dos processos estruturadores das ONGs. Neste caso, ressalte-se a novidade da abordagem, uma vez que não encontramos referência na literatura de muitos trabalhos que se utilizem da perspectiva teórico-metodológica de redes sociais para a compreensão dos processos subjacentes à organização e funcionamento das ONGs ${ }^{4}$ 
b) discussão dos dados da pesquisa, objetivando testar as hipóteses mencionadas acima.

\section{Redes Sociais, Capital Social e Terceiro Setor: discussão da literatura}

Apresentaremos nesta parte uma revisão da literatura sobre Redes e ONGs. Objetivamos introduzir o leitor às principais questões discutidas por especialistas e que são importantes para a análise de nossos dados empíricos. Tal como em diversos campos das ciências sociais, a literatura sobre redes e ONGs é bastante extensa. As questões aqui apresentadas foram selecionadas e portanto refletem as preocupações do autor. Esta seção está organizada em duas partes: a) discussão sobre redes e associações voluntárias de uma maneira mais extensa, objetivando problematizar o papel das associações voluntárias nas sociedades contemporâneas, especialmente enfatizando as tendências de mudança recentemente observadas; b) sobre a relação entre o desenho das redes sociais e os processos organizativos das ONGs. Aqui ensaiaremos uma seleção de assuntos discutidos na literatura que comentem ou indiquem metodologicamente caminhos para análise da importância da variável "rede social" para a compreensão dos desenhos organizativos das ONGs. Interessa-nos, de modo especial, comentar questões relevantes às nossas hipóteses de trabalho (esboçadas na introdução e que serão testadas na terceira parte deste artigo): sobre a funcionalidade de determinados desenhos de redes na alocação de recursos das ONGs, dando por conseguinte o suporte necessário ao bom funcionamento destas instituições.

a) Algumas questões gerais sobre as associações voluntárias, enquanto instrumentos importantes para a compreensão dos processos estruturadores das ONGs

As associações voluntárias têm atraído recentemente a atenção dos cientistas sociais devido ao fato de, com o aparente colapso do Estado do Bem-Estar Social no fim da década de 70, as profundas mudanças por que tem passado o sistema capitalista desde então (a crise 
do mundo do trabalho e sua subseqüente desregulamentação, os processos de globalização e desterritorialização), o chamado Terceiro Setor tem se constituído uma importante alternativa para as políticas anteriormente desenvolvidas pelos Estados nacionais. ${ }^{5}$ Uma outra importante questão também é destacada entre os estudiosos: a vitalidade dessas associações voluntárias também implica no revigoramento da democracia. Depois do trabalho de Putnam (1993) e outros que enfatizam a importância da cultura cívica, e as relações existentes entre esta idéia e a do ativismo democrático, as associações voluntárias têm sido vistas não somente enquanto instrumentos que podem reduzir a pobreza, mas também enquanto importantes instrumentos que podem ser usados para aprimorar as instituições democráticas.

Estas mudanças recentemente observadas têm se constituído em objeto de controvérsia entre os estudiosos. De um lado, opiniões liberais tendem a ver a redução do papel do Estado e a subseqüente emergência da competição uma condição fundamental para o bom funcionamento do sistema capitalista, promovendo desta forma o bem-estar. ${ }^{6}$ Críticos, entretanto, objetam: o neoliberalismo, com o anti-estatismo, glorificação do empreendedor, individualismo e competição, leva à fragmentação social. $^{7}$

Observamos, portanto, na literatura das ciências sociais, uma vasta gama de interpretações do Terceiro Setor e sua importância para a sociedade. Se for correto afirmar que a emergência do Terceiro Setor e as recentes mudanças nas sociedades ocidentais são contemporâneas, o seu florescimento é uma das características desta nova era, e pode significar novos rearranjos nas estruturas de sociabilidade. Como advoga Rosanvallon (1981), esta reestruturação pode indicar o período pós Welfare State, no qual a regulação social se dá principalmente através dos processos de "infra-sociabilidades", quer dizer, localizados na vida cotidiana dos indivíduos.

Aqui o que nos interessa é verificar as possibilidades destas populações de baixa renda em desenvolver ações que facilitem a administração dos negócios locais, usando fórmulas associativas encontradas na sociedade civil (associações de bairros, ONGs, grupos religiosos, etc.), e agindo independentemente ou em direta cooperação com o Estado. 
Essas questões acima discutidas remetem a um tema que tem recebido larga atenção nas discussões mais recentes: o revigoramento das redes de solidariedade social baseadas na sociedade civil, através do estabelecimento de mecanismos de provisão de serviços, cujo controle não é necessariamente localizado no Estado, mas na sociedade civil. Tais redes, popularmente organizadas com contribuições de ONGs, associações de bairros, grupos religiosos, etc. Tem estruturado o que poderíamos chamar de "economia popular urbana", enquanto solução para a crise fiscal e a falência do Estado do Bem-Estar Social, bem como enquanto importantes instrumentos na formação de laços de identidade e no estabelecimento de práticas associativas.

As ONGs e os movimentos populares são os atores estratégicos neste processo: ações públicas empreendidas por fora da esfera estatal. Seguindo recentes transformações nas sociedades contemporâneas, a sociedade civil tem se reestruturado, gerando novas formas de solidariedade. Alguns autores, como Rosanvallon (1981), por exemplo, consideram que a crise Estado do Bem-Estar Social é uma crise de solidariedade. Mudanças no sistema sociopolítico e de legitimação resultaram, de acordo com Rosanvallon, na emergência de outros espaços de regulação, que demandariam novos processos de legitimação. Neste sentido, a regulação estatal keynesiana seria substituída por autogestão e regulação intra-social. Estas novas formas de solidariedade resultam em uma importante visibilidade de atores como as ONGs e os movimentos sociais. Suas práticas, usualmente associadas com processos inseridos em práticas não mercantis, seriam bastante significativas neste momento.

Como afirmamos acima, as mudanças recentes no sistema socio político das sociedades contemporâneas parecem indicar que estas novas formas de solidariedade estão sendo redefinidas. De acordo com Klaus Offe (1975), durante o período do "capitalismo tardio" o principal instrumento de articulação nesta sociedade do trabalho, os partidos políticos e os sindicatos, perderam importância para os novos movimentos sociais e as ações corporativas. Mais recentemente, associações voluntárias (movimentos sociais, ONGs, movimentos de auto-ajuda, entidades filantrópicas, etc.) podem ser observadas nesta onda de novas redes de solidariedade. 
Esta fórmula organizativa da sociedade civil pode ser pensada enquanto um "terceiro setor", um espaço de sociabilidade fora do mercado e do Estado (embora com importantes conexões entre estas duas esferas), o qual, com as importantes mudanças verificadas recentemente, tem crescido em importância. O Terceiro Setor pode ser definido enquanto

... atividades autônomas, organizadas por voluntários na microesfera do social O Terceiro Setor é constituído pela união de incontáveis voluntários, empenhados em combater a miséria e interromper os processos de degradação do meio ambiente. A maioria destes grupos coloca grande valor na administração autônoma. No campo prático, [o terceiro setor] avança através do espaço abandonado pelo mercado e pelo Estado, em razão de baixos rendimentos ou falta de financiamento de algumas atividades. (Kurtz, 1995, p. 5)

O recente florescer deste Terceiro Setor tem resultado em uma profunda transformação nas práticas de solidariedade. Com efeito, podemos dizer que arranjos de solidariedade enraizados na sociedade civil e estruturados nas esferas não mercantis da economia são bastante antigos - pode-se dizer que estas práticas sempre existiram em sociedades humanas. Douglas (1987, p. 43-54), por exemplo, assinala que em 1601 o Parlamento Inglês instituiu o Statute of Charity Associations, que pode ser considerado a primeira peça jurídica regulamentando atividades filantrópicas. Os processos sociais resultantes destas organizações são enraizadas em estruturas de troca que não têm necessariamente base mercantil, indo desde trocas de presentes até estruturas de auto-ajuda organizadas pela comunidade para prover de serviços e bens os membros mais vulneráveis da comunidade (idosos, crianças, enfermos). Este assunto é discutido em detalhes por Mauss e seus seguidores, em sua famosa teoria da Dádiva. ${ }^{8}$ Por outro lado, práticas não mercantis, características de estruturas de solidariedade localizadas na sociedade civil, têm passado por fases críticas de declínio com a expansão das sociedades mercantis. Como nos mostra Laville (1994),

Com o advento de sistemas de macro-regulação social formados e consolidados na era da expansão capitalista, a economia não monetária se retrai. A economia monetária integra os setores mercantil e não mercantil, reconciliando competitividade econômica com coesão social e incrementando a renda monetária que é distribuída entre 
diferentes grupos sociais. $\mathrm{O}$ que resulta em um equilíbrio durável. No processo de produção, conflitos são confinados à divisão do valor agregado e à organização das relações salariais. O ganho do poder de consumo é trocado por poder na esfera do trabalho. Fora da produção, com o enfraquecimento da sociabilidade tradicional, a solidariedade é reduzida a uma forma abstrata que, através da burocratização dos serviços sociais, tende a ser encarada antes como assistência que como um sistema de solidariedade ativa.

As instituições que fazem parte deste setor não mercantil, entretanto, estão sempre presentes e se constituem em um dos pilares da democracia contemporânea. Este é o argumento de Tocqueville (1977), em sua Democracia na América, onde mostra as associações civis americanas provendo as fundações da democracia de base. O que se tem observado recentemente é o renascimento destas organizações de base, que têm ganhado uma visibilidade política não usual. A crise do Estado do Bem-Estar Social, a desregulamentação das políticas estatais e o retorno ao local indicam um processo de mudanças bastante intenso na prática do Estado Intervencionista que, de certa forma, contribuiu para o revigoramento das associações voluntárias. A literatura neste ponto é enfática: estas organizações progressivamente assumem uma importância decisiva na geração de serviços e na provisão de bens públicos. Não existe, entretanto, consenso sobre qual a real dimensão desta esfera na organização destas atividades. Reconhece-se que o Estado tem mudado profundamente, mais ainda mantém sua importância enquanto agente regulador, e em um número significativo de casos, esta nova ação agora é realizada em cooperação com a sociedade civil (agências não-governamentais), basicamente situada na esfera do poder local.

As associações voluntárias constituem um importante reino de instituições diversas, indo desde as ONGs e Igrejas até instituições filantrópicas e associações de bairro. Estas instituições são consideradas parte do Terceiro Setor, e podem ser definidas enquanto organizações que não integram o aparato do Estado, não têm objetivos lucrativos e normalmente envolvem participação voluntária de seus membros, isto é, trabalho não remunerado. Freqüentemente estas organizações produzem bens públicos. O que significa que os benefícios por ela produzidos atingem outras pessoas além de seus membros. 


\section{b) ONGs e redes sociais $^{9}$}

O recente florescimento do Terceiro Setor lhe coloca problemas que antes não se apresentavam tão importantes. As antigas instituições filantrópicas e de caridade estruturavam-se em padrões organizativos mais simples, com mecanismos de financiamento e alocação de recursos humanos menos profissionalizados. Normalmente organizadas em bases de ação religiosas, essas instituições - importantes fornecedoras de serviços de assistência para as comunidades mais carentes - contavam com o suporte da comunidade religiosa que fornecia sustentação financeira e apoio no recrutamento de trabalho voluntário. As ações empreendidas - muitas delas em caráter emergencial como coleta de donativos para desabrigados, mas também outras mais permanentes como organização de escolas e hospitais - contavam com um fluxo de recursos relativamente estáveis. Ao contrário das ONGs deste início do século, as demandas por eficiência, profissionalização dos quadros e expertise contábil - indispensáveis para fazer face à crescente competição por recursos não eram requeridas de forma tão intensa. ${ }^{10}$ Também problemas decorrentes da competição não estavam tão gravemente presentes.

Processos organizativos e estrutura de alocação de recursos constituem-se em importantes questões inscritas na agenda de pesquisa das ONGs contemporâneas. Além das questões relativas a processos de mudança de ordem mais geral - como é o caso da agenda de reforma de Estado, crise do Welfare State, reestruturação produtiva, etc. - aquelas inscritas no esclarecimento do modus operandi das ONGs são cada vez mais pesquisadas. Como se estruturam, quais são as suas principais fontes de recursos, que características organizacionais são mais significativas?

Estes processos são analisados aqui a partir do ponto de vista da Teoria das Redes Sociais (social network analysis) As redes sociais são as pontes que ligam os indivíduos às instituições sociais e estruturam suas biografias em inserções sociais que garantem suas identidades. Este conceito garante a compreensão de complexos processos sociais vivenciados em nível microssociológico, a partir de sua relação com fenômenos situados ao nível macro. Deste modo,

Network analysis se origina a partir de uma idéia simples, mas poderosa: que a tarefa principal dos sociólogos é estudar a estrutura social. Embora a ênfase na estrutura social pareça óbvia, é importante 
mostrar o que realmente significa. Ela desconsidera a análise sobre por que as pessoas agem e enfatiza os condicionantes estruturais de suas ações... A maneira mais direta de estudar a estrutura social é analisar os padrões de ligações entre seus membros. Network analysis procura as estruturas profundas - padrões de redes por baixo dos sempre freqüentes complexos sistemas sociais em sua superfície. Os analistas de redes tentam descrever estes padrões e usam estas descrições para aprender como as estruturas de redes influenciam o comportamento social e produzem mudança. Suas descrições estão baseadas no conceito de laços (ties), conectando nódulos (nodes) em um sistema social - laços que conectam pessoas, grupos, organizações... Network analysis quer saber como as propriedades de natureza estrutural afetam comportamento para além das prescrições normativas, atributos pessoais e relações de natureza diática. Os analistas das redes concentram-se na estrutura, estudando como os padrões dos laços estabelecidos em uma rede provêem oportunidades e limitações porque influem no acesso das pessoas e instituições a recursos como informações, riqueza e poder. As análises de redes, portanto, tratam sistemas sociais enquanto redes de relações de dependência resultantes de acessos diferenciais a recursos escassos. (Wellman, 1983, p. 156)

As prática sociais que resultam em alocação de recursos por fora do mercado e do Estado - as que formam as associações voluntárias se estruturam em redes sociais com características relativamente singulares. Assim, como nos mostra Wellman (1988, p. 28), “questões relativas a acesso a recursos estão estreitamente associadas com o desenho das redes... Número razoável de estudos demonstraram os efeitos de diferentes padrões de redes no acesso a recursos". Diversos tipos de recursos não podem ser obtidos através do mercado. Informações, apoio emocional, suporte financeiro, ou ajuda na guarda de crianças ou em caso de doença são exemplos que facilmente se replicam no cotidiano de cada um de nós. Estando presente nas redes de amigos, parentesco ou vizinhança, ou nas organizações de trabalho voluntário, estes recursos são alocados de forma particular, não obedecendo à lógica do mercado ou do Estado. Também, aparentemente, as redes sociais subjacentes à alocação destes recursos se dão de forma bastante particular.

As redes de solidariedade são lembradas enquanto instrumento importante de enfrentamento de situações adversas pelos pobres urbanos, principalmente em situações de insegurança econômica e de falência 
dos serviços públicos. Com efeito, como nos mostra Granovetter (1981, p.107), "redes de laços fortes parecem estar ligadas tanto à insegurança econômica quanto à falta de serviços sociais. Desde que a taxa de desemprego seja alta, a ameaça de viver na pobreza é real; desde que grandes segmentos da população encontra dificuldades para ter acesso a serviços médicos, creches e outros serviços sociais, podemos esperar uma maior intensidade da busca de laços sociais fortes". ${ }^{11}$

Mas também existem outros mecanismos produtores de solidariedade localizados por fora do Estado e do mercado que não se estruturam propriamente em redes sociais de laços sociais forte, como é o caso de solidariedades produzidas por redes egocentradas. As ações empreendidas pelas associações voluntárias são o exemplo mais marcante. ${ }^{12}$ Godbout descreve estas ações, distinguindo-as daquelas empreendidas pelas esferas estatal ou mercantil:

... O fato de que o princípio-motor da ação tenha origem no laço que existe entre os membros da associação ou entre a associação e a pessoa que recebe ajuda. Todos insistem neste aspecto particular que distingue esta ação da intervenção pública: os laços comunitários entre o prestador e o prestatário do serviço. Esta ausência de ruptura é particularmente evidente nos grupos de ajuda mútua. Mas também está presente em todo o lugar: 'aqui não é uma repartição pública', dizem, por exemplo os que trabalham em uma ONG. Esta ausência de ruptura se manifesta igualmente pela insistência na recusa de superioridade a partir da competência profissional, criando um fosso entre o cliente e o especialista: 'somos todos parecidos; podemos compreender o problema daqueles que vêm nos ver; nós somos como eles. (Godbout, 1992, p. 106)

Aqui, diferentemente das ações empreendidas a partir dos laços estabelecidos nas redes egocentradas, a presença de laços fortes não é condição sine qua non. Os mecanismos geradores de solidariedade se apoiam em ações empreendidas coletivamente, geralmente orientadas para a produção de bens públicos. Estas ações podem ser caracterizadas ou não enquanto ações coletivas: com efeito, muitas destas ações, resultantes de práticas filantrópicas ou de trabalhos voluntários, dificilmente poderiam ser categorizadas enquanto atos resultantes do esforço coletivo para a satisfação de necessidades egoísticas, que não podem ser satisfeitas individualmente. Dificilmente, portanto, poderse-ia adequar estes fatos à teoria da olsoniana das ações coletivas, 
caracteristicamente utilitarista, ${ }^{13}$ o que não significa dizer que os indivíduos envolvidos em ações desta natureza não sejam motivados racionalmente. É o que nos mostra Coleman, quando afirma que "algumas obrigações se originam da criação intencional de reciprocidade de uma pessoa que faz alguma coisa para uma outra" (Coleman, 1994, p. 309). Estas ações também se estruturam a partir de desenhos particulares de redes sociais. Embora não se tenha clareza a respeito da relação entre estas ações e estruturas particulares de redes sociais que a suportam (Burt, 1992, p. 60), haveria uma desenho particular das redes, tanto no que diz respeito aos atores que participam destas ações, quanto em relação às próprias instituições organizadas para o empreendimento destas ações, em sua relação com o ambiente social onde estão inseridas.

Aqui, alguns pontos merecem consideração. As estruturações societárias que resultam em estabelecimento de ações fundadas em organizações voluntárias se constituem em uma importante fonte de recursos para as comunidades envolvidas. O resultado mais significativo, ao lado dos recursos alocados e conseqüentemente dos benefícios resultantes de sua fruição, é a crescente capacidade destas comunidades em lidar com os negócios públicos, seja empreendendo ações autonomamente, seja endereçando à esfera pública suas reivindicações. Putnam (1992) chama isto de cultura cívica. Neste sentido, comunidades que carecem de cultura cívica estariam imbuídas de práticas obstacularizadoras de formação de estoque deste tipo de capital; estariam, portanto, estruturadas em padrões de sociabilidade que não facilitariam a formação de uma cultura cívica. É o que Banfield (1958) aponta, em seu estudo sobre uma comunidade do sul da Itália, na existência do que ele designa familismo amoral: padrões de comportamento que resultariam em apatia e relativamente isolamento da esfera pública e do empreendimento de ações públicas via organizações voluntárias. Este tipo de padrão comportamental, embora Banfield não indique diretamente, estaria ligado a uma estrutura particular de redes sociais, obstacularizadoras da formação de uma cultura cívica.

As ações, deste modo, estabelecidas a partir dessas estruturações particulares de sociabilidade, seriam potenciais carreadoras de recursos para seus protagonistas. Estes, portanto, teriam um estoque de capital, cujas características seriam distintas do capital físico ou do capital 
humano, comumente descritos na literatura econômica. Este tipo de capital, designado de capital social, é definido da seguinte maneira:

Capital social é definido por sua função. Não é uma entidade única, mas uma variedade de diferentes entidades tendo duas características comuns: consistem todas em algum aspecto da estrutura social, e facilitam algumas ações de indivíduos que estão na estrutura. Como outras formas de capital, capital social é produtivo, tornando possível a realização de alguns objetivos que não poderiam ser alcançados na sua ausência. Como capital físico e capital humano, capital social não é totalmente negociável (fungible), mas o é em relação a atividades específicas. Uma dada forma de capital social que é valioso facilitando certas ações, pode não ter valor ou mesmo ser prejudicial para outras ações. Diferentemente de outras formas de capital, o capital social herda a estrutura de relações entre as pessoas. Ele não está alojado nem em indivíduos nem em infra-estrutura produtiva... capital humano é criado mudando pessoas, dando-lhes habilidades que as tornam capazes para agir em novos ambientes. Capital social, por sua vez, é criado quando as relações entre pessoas muda de forma que facilita a ação. Capital físico é totalmente palpável (tangible), estando incorporado em formas materiais observáveis; capital humano é menos materializável, estando incorporado em habilidades e conhecimentos adquiridos pelo indivíduo; capital social é ainda menos palpável, porque está incorporado nas relações entre as pessoas. (Coleman, 1994, p. 303-304)

O estoque de capital social disponível nas comunidades, portanto, seria o elemento potencializador de seu desenvolvimento - ao lado dos capitais humano e físico; este tipo de capital, diferentemente dos outros, seria estruturado a partir dos vínculos estabelecidos a partir das relações entre as pessoas. ${ }^{14}$ Seria portanto função da natureza particular das redes sociais estruturadas, funcionais, o seu desenvolvimento. Haveria também uma certa relação entre as redes sociais egocentradas (que instrumentalizam um tipo de solidariedade, fundado nos laços fortes) e o nível de organização comunitária, operado a partir de suas associações voluntárias. É o que chamo de sustentabilidade das organizações voluntárias. Inicialmente estruturadas a partir de ações voluntárias estabelecidas em uma comunidade para o empreendimento de práticas visando à produção de bens públicos, estas organizações construíam suas identidades a partir da idéia de comunidade, locais de conviviabilidade e de estabelecimento de laços de pertencimento, que 
se traduziam no esforço coletivo para a produção do bem-estar. Outras formas de identidade não necessariamente ligadas a uma comunidade de base territorial também seriam estruturadas a partir de redes, formadoras de capital social. O que se traduziria no que Wuthnow (1998, p. 7) designa de envolvimento cívico, "participação em atividades sociais que tanto estabelece mediação entre cidadãos e o governo quanto provê meios para cidadãos perseguirem objetivos comuns com ou sem ajuda do governo". O que caracteriza, deste modo, uma associação voluntária é exatamente esta vinculação com uma prática que se consubstancia a partir de um estoque de capital social, que por sua vez depende de um padrão de estruturação de sociabilidade particular

As organizações voluntárias - também conhecidas por Terceiro Setor - podem ser compreendidas a partir das questões levantadas acima. De um lado, prováveis mudanças nas sociedades contemporâneas que estruturam um padrão de práticas mais favoráveis ao desenvolvimento do Terceiro Setor ${ }^{15}$ que, por sua vez, também se adaptaria a novos padrões de sociabilidade. Os padrões organizativos das associações voluntárias contemporâneas teriam um perfil particular, consoante com as novas formas de sociabilidade. Estas mudanças e conseqüentemente as novas formas de solidariedade estabelecidas não obedeceriam, entretanto, a um padrão linear, uniforme. Há que se assinalar, de um lado, que o processo ainda está em formação e, que, de outro, as inovações são absorvidas diferenciadamente segundo grupos sociais, regiões ou outros elementos que modelam as sociedades modernas, caracteristicamente estabelecidas em um padrão de desigualdade social.

Estas novas formas de sociabilidade também modificam profundamente as práticas organizativas do chamado Terceiro Setor que, como vimos, se orienta recentemente para um padrão de ação mais profissionalizante, abandonando em parte os ideais filantrópicos ou estruturações de solidariedade baseadas na caridade cristã. O Terceiro Setor ainda se constitui em instrumento importante de geração de solidariedade por fora do mercado, mas as suas práticas organizativas estão cada vez mais dependentes de princípios de eficiência e eficácia na aplicação de recursos, muitas vezes inclusive com critérios alocativos decididos a partir das instituições financiadoras dos recursos, que também se reestruturam profundamente. Tem-se verificado, recentemente, uma crescente importância dos fundos públicos ${ }^{16}$ no financiamento das ações 
das ONGs e, para o caso da América Latina, ${ }^{17}$ a diminuição de recursos originários da cooperação internacional, embora ainda sejam importantes.

Um importante elemento a considerar na análise das ONGs diz respeito às estratégias de mobilização de recursos empregadas e o conseqüiente sucesso para o financiamento de suas ações. As ONGs, como vimos, tornam-se cada vez mais dependentes de fundos públicos ou de financiamentos externos à cooperação voluntária de seus membros, de um lado; por outro, o florescimento das ações do Terceiro Setor resulta em uma maior competição por recursos, o que significa que estas instituições são cada vez mais levadas a pensar em estratégias de arrecadação de recursos, indispensáveis para o desenvolvimento de suas ações.

$\mathrm{Na}$ análise dos processos de como as ONGs constróem suas estratégias para alocar recursos para seus projetos, há de se considerar as estruturações das redes sociais destas instituições enquanto importantes elementos na explicação do sucesso (ou fracasso). A análise das redes permitiria, além dos processos de articulação política, ${ }^{18}$ a explicação de como mecanismos alocativos são influenciados por posições dos atores na estrutura das relações sociais

Neste sentido, importantes estudos já realizados sobre estrutura de redes podem ser bastante úteis para a análise das ONGs. Como, por exemplo, a Teoria de Trocas, que analisa as redes de trocas - constituídas por "um conjunto de duas ou mais relações", que se estruturam na base de troca de vários conteúdos (afetivos, informacionais, aconselhamento, relações de influência, etc.) (Cook, 1995, p. 180); ou estudos sobre processos políticos utilizando-se da teoria de mobilização de recursos. Estudos que mostram como padrões de laços entre grupos de interesse estruturam coalizões, clivagens e relações competitivas e como laços diretos e indiretos ligam diferenciadamente os indivíduos e grupos a recursos" (Wellman, 1988, p. 29); ou a teoria das redes de troca, ${ }^{19}$ que objetiva "prever como acontecem as distribuições negociadas de recursos em padrões de rede consistindo de atores que inter-relacionam entre si, individuais ou corporativos (Marykousky, p. 198); ou ainda, como a posição do indivíduo (ou instituição) na estrutura de redes pode interferir na posição estrutural do ator. É o que constata, por exemplo Burt, na 
análise das localizações dos empreendedores nas redes corporativas e as possibilidades de ganhos ou mesmo acesso diferenciado à estrutura social. Atores com a mesma posição na estrutura social podem, de acordo com sua posição em uma estrutura de redes, ter mais ou menos êxito em processos de mobilidade social, quer dizer, mais ou menos êxito no acesso a recursos.

Não existem muitos estudos sobre a relação entre desenho de redes e processos de mobilização de recursos no terceiro setor. Ou sobre desenhos organizacionais e estruturação de padrões de competição. Alguns estudos existentes tratam o assunto desconsiderando a variável "rede social", embora muitas vezes possamos vislumbrar algumas questões que poderiam ser analisadas com mais acurácia se introduzirmos essa variável. É, por exemplo, quando confrontamos a recente necessidade das ONGs em se profissionalizar (expertise contábil e de seus quadros operacionais) diante da demanda de seus financiadores e as conseqüentes mudanças organizacionais decorrentes desse fato. Aqui se coloca, como questão importante, não somente o redesenho organizacional (em certa medida já analisado em alguns estudos), mas também a competição por recursos que se estabelece neste campo ocupacional. ${ }^{20}$ A posição na estrutura social de um determinado ator (neste caso, de uma ONG) é também determinada por sua posição na estrutura da rede social. Fator muito importante a ser considerado é que as ONGs - diante de um quadro de relativa escassez de recursos constróem estratégias para alocar recursos portanto deve ser considerado o fato de que há uma competição relativamente acirrada entre ONGs congêneres, e que um dos elementos a ser considerados para o êxito são os círculos sociais e contatos com uma gama a mais ampla possível de atores, possibilitando desta forma posições relativamente privilegiadas no círculo social de atores envolvidos neste campo ocupacional.

\section{Redes e Terceiro Setor: um estudo empírico de redes de ONGs na cidade do Recife}

Ensaiaremos nesta parte, a partir de dados extraídos de 40 Organizações Não-Governamentais que atuam na cidade do Recife, a análise e verificação das hipóteses anunciadas na introdução deste artigo. A nossa amostra apresenta as seguintes características: 
a) são instituições relativamente pequenas, utilizando-se em sua maioria de trabalho remunerado, mas com uma boa proporção delas (55\%) empregando algum trabalho voluntário; ${ }^{21}$

b) o seu staff é relativamente reduzido: $55 \%$ das ONGs entrevistadas empregam até 20 pessoas; movimentam, em média, $\mathrm{R} \$ 600.000,00$ por ano, com recursos originários predominantemente da cooperação internacional $(59,6 \%$ das fontes de recursos citadas); ${ }^{22}$

c) as ONGs integrantes de nossa amostra foram fundadas, em sua maior parte há no máximo 20 anos. ${ }^{23}$ Parcela insignificante delas tem um tempo de fundação maior de 30 anos - somente $5 \%$ - e das que foram fundadas há menos de 20 anos, $65 \%$ têm menos de 10 anos de existência;

d) as ONGs entrevistadas trabalham principalmente com crianças, adolescentes e mulheres - com trabalhos de aconselhamento, produção de serviços e assessoria a movimentos populares - e educação, com uma abrangência geográfica concentrada na Região Metropolitana do Recife (embora tenham uma área de influência bem maior que a cidade do Recife ou sua Região - somente 37,5\% das ONGs entrevistadas atuam na cidade do Recife ou Região Metropolitana).

A nossa amostra não pretende ser representativa do universo das ONGs atuando na Região Metropolitana do Recife, mas algumas características destas ONGs também estão presentes nas instituições que compõem a nossa amostra. Algumas, com as informações obtidas nas entrevistas confirmando; outras, apenas tendências que se esboçam nos dados de forma indireta.

As ONGs podem ser definidas, de maneira geral, como instituições que "fornecem benefícios públicos a partir de fundos privados... e que constituem uma alternativa ao governo, permitindo uma maior diversidade de provisões sociais do que poderia ser suportada pelo Estado" (Douglas, 1987, p. 51). Neste sentido, as organizações cujo objetivo principal é o de prover serviços públicos (para quem quer que o deseje), são analisadas a partir de quatro questões principais: a) Como elas se organizam? b) Quais são as suas funções? c) Qual é a sua clientela? d) Quais são as áreas onde se verificou recentemente crescimento significativo? 
Scherer-Warren (1995), por exemplo, afirma que

Literatura recente parece indicar diversas tendências de ações das ONGs. Nos países em desenvolvimento, existe uma ênfase no trabalho realizado no campo da filantropia e altruísmo, ao passo que nos países desenvolvidos e no Leste Europeu a ênfase recai nos projetos enfatizando questões ligadas ao desenvolvimento da cidadania, democracia, organização popular, auto-determinação e justiça social.

A nossa amostra é composta por ONGs que têm uma agenda bastante diversificada, com áreas de atuação as mais variadas possíveis. É possível, entretanto, perceber claramente que a ênfase na prestação de serviços a populações mais carentes é o que poderíamos caracterizar como vocação destas ONGs. ${ }^{24}$ Da mesma forma, quando perguntados sobre qual seria o papel de uma ONG - o que poderíamos considerar sobre o que pensam os entrevistados a respeito de sua missão uma parte significativa de respostas está ligada à promoção de ações relativas à promoção de melhores condições para populações mais desfavorecidas - produção de serviços sociais e promoção para o desenvolvimento da sociedade, com $31,1 \%$ e $23,0 \%$ das respostas, respectivamente.

No que diz respeito a tendências de evolução no setor, nossos dados não nos permitem conclusões definitivas, pois não dispomos de séries históricas. Alguns pontos, entretanto, devem ser considerados à luz de estudos sobre o assunto. Uma primeira questão importante diz respeito à vocação das ONGs e como a sua prática se ajusta às demandas historicamente particulares da sociedade. É fato que as ONGs têm passado por um processo de profissionalização (que se verifica principalmente a partir do fato de que seu staff seja cada vez mais formado por pessoas com formação técnica, que tenha por ocupação principal a atividade desenvolvida na instituição, e que o trabalho voluntário, não remunerado e não especializado, seja cada vez menos importante); que as fontes de financiamento tenham se deslocado das tradicionais contribuições oriundas de instituições religiosas e caritativas para instituições de cooperação internacional ${ }^{25}$ e agências governamentais. No caso das ONGs que pesquisamos, a cooperação internacional responde pela maioria dos recursos, com 59,6\%; a segunda fonte de recursos é a governamental, com $23 \%$ das instituições pesquisadas. ${ }^{26}$ Os dados não nos permitem afirmar que tenha havido uma tendência de diminuição de aporte de recursos da cooperação 
internacional e uma maior importância de financiamento originário das instituições governamentais. A literatura aponta esta tendência a partir da década de 80 , com a recessão e os processos de reestruturação do Estado do Bem-Estar Social. Com efeito, Clarke (1996, p. 2) afirma que "governos em países em desenvolvimento, devido à recessão econômica, têm sido levados a apoiar ONGs em programas de ações sócio-econômicos". Programas de reestruturação do Estado, ao lado de uma crescente visibilidade das organizações da sociedade civil (das quais as ONGs são a parte mais representativa) resulta em um fluxo mais intenso de recursos governamentais no apoio das ações das ONGs.

O Terceiro Setor no Brasil se constitui em importante área na provisão de serviços para populações pobres e também significativa fonte de geração de empregos. É difícil, entretanto, avaliar a sua dimensão. As informações disponíveis são escassas, e muitas vezes controversas. As fontes não estão interrelacionadas e nenhuma delas isoladamente provê uma visão adequada da totalidade do Terceiro Setor. A Secretaria da Receita Federal, o Ministério do Bem-Estar Social, e o IBGE são as fontes de informação mais utilizadas. Os dados que apresentamos a seguir são extraídos de um relatório sobre o Terceiro Setor no Brasil (Melo, 1997), ${ }^{27}$ que utiliza, entre outras, estas fontes de informação. Conforme afirma esse documento, a falta de dados sistematizados provavelmente resulta em um quadro que não reflete adequadamente a realidade, subestimando a importância do Terceiro Setor. Desta forma, provavelmente não foram computadas informações de atividades mais informais como associações de moradores, grupos religiosos e outras entidades que provêem importantes serviços para suas comunidades.

Mesmo considerando uma provável subestimação, o Terceiro Setor ocupa uma posição bastante importante. Com efeito, 220.000 instituições foram classificadas enquanto pertencentes ao Terceiro Setor, em 1991, ${ }^{28}$ de acordo com dados da Secretaria da Receita Federal. Considerando pessoas ocupadas por grupos de atividades, as áreas de Educação, Saúde e Cultura e Recreação são as que concentram maior número de pessoas empregadas, com $34,04 \%, 16,44 \%$ e $15,68 \%$, respectivamente.

Este setor vem apresentando um crescimento bastante significativo. Com efeito, no período 1991-1995, o crescimento médio de pessoas empregadas foi de cerca de $45 \%$, o que significa um índice 
bem maior que o da força de trabalho brasileira em geral, que, no mesmo período, apresentou um crescimento médio de 19,8\%. ${ }^{29}$ Entre os grupamentos de atividade, as associações profissionais e os grupos recreativos e culturais foram os que apresentaram maiores taxa de crescimento, com $94,5 \%$ e $92,09 \%$, respectivamente.

Tabela 1 - Pessoas empregadas no Terceiro Setor, segundo atividade principal -1995

\begin{tabular}{lrr}
\hline Atividades & Número & \multicolumn{1}{c}{$\%$} \\
\hline Associações Profissionais & 99,203 & 8.86 \\
Cultura e Recreação & 175,540 & 15.68 \\
Assistência Social & 169,663 & 15.15 \\
Direitos Humanos & 5,361 & 0.48 \\
Educação & 381,098 & 34.04 \\
Religião & 93,769 & 8.37 \\
Saúde & 184,040 & 16.44 \\
Outras & 10,904 & 0.97 \\
\hline TOTAL & $\mathbf{1 , 1 1 9 , 5 7 8}$ & $\mathbf{1 0 0 . 0 0}$
\end{tabular}

Fonte: MELO, Marcus André. Texto preparado para o Relatório de Desenvolvimento Humano, Brasil. Brasília, 1997.

Tabela 2 - Crescimento das pessoas empregadas no Terceiro Setor, segundo atividades principais - Brasil - 1991-1995

\begin{tabular}{lc}
\hline Atividades & Crescimento \% \\
\hline Associações Profissionais & 94,57 \\
Cultura e Recreação & 92,90 \\
Assistência Social & 69,67 \\
Direitos Humanos & 55,08 \\
Educação & 29,32 \\
Religião & 29,12 \\
Saúde & 17,97 \\
Todas as atividades & 45,16 \\
Outras & 63,09 \\
\hline
\end{tabular}

Fonte: MELO, Marcus André. Texto preparado para o Relatório de Desenvolvimento Humano, Brasil. Brasília, 1997. 
Por sua vez, a cidade do Recife concentra um número relativamente importante das ONGs existentes na Região Nordeste. Como nos mostra o cadastro da ABONG, 53\% das ONGs da Região, cadastradas pela ABONG, localizam-se no Estado de Pernambuco; em Recife concentram-se $41 \%$ do total das ONGs da Região (Tabela 3). ${ }^{30}$

\section{Tabela 3 - ONGs filiadas à Associação Brasileira de ONGs - Região Nordeste em \% por Estado - 1995}

\begin{tabular}{lllllllllll}
\hline & AL & BA & CE & MA & PB & PE & PI & RN & SE & TOTAL \\
\hline $\begin{array}{l}\text { Capital } \\
\text { Outras }\end{array}$ & 02 & 05 & 05 & 05 & 03 & 41 & 02 & 02 & 03 & 68 \\
Cidades & - & 07 & 03 & 01 & 04 & 12 & 05 & - & - & 32 \\
\hline TOTAL & $\mathbf{0 2}$ & $\mathbf{1 2}$ & $\mathbf{0 8}$ & $\mathbf{0 6}$ & $\mathbf{0 7}$ & $\mathbf{5 3}$ & $\mathbf{0 7}$ & $\mathbf{0 2}$ & $\mathbf{0 3}$ & $\mathbf{1 0 0}$ \\
\hline
\end{tabular}

Fonte: As ONGs e a realidade brasileira. Cadernos da ABONG, n. 6, jun. 1996

OBS: AL - Alagoas; BA - Bahia; CE - Ceará; MA - Maranhão; PB - Paraíba; PE - Pernambuco; PI - Piauí; RN - Rio Grande do Norte; SE - Sergipe

Essas ONGs atuam em diversas áreas. Recentemente tem se verificado um crescimento em quase todas as áreas de intervenção, o que pode ser explicado pela diversificação dos trabalhos desenvolvidos pelas instituições, estratégia utilizada para possibilitar uma maior flexibilidade na captação de recursos, de um lado, e pela perspectiva de trabalhar os temas globalmente, considerando suas inter-relações, por outro (ABONG, 1996, p. 7). Entretanto, como nos mostra a Tabela 04, os trabalhos das ONGs da Região Nordeste tem se concentrado em certos setores. Educação e organização popular, por exemplo, são alvo de atuação de mais da metade das instituições atuantes da região. Atividades relacionadas ao meio ambiente têm recentemente observado um crescimento bastante significativo: em 1990, mantinham atividades relacionadas a este tema $20 \%$ das ONGs; em 1995, o número de instituições crescia para $32 \%$. 


\section{Tabela 4 - ONGS por área de atuação - Região Nordeste 1990-1995}

\begin{tabular}{l|cc}
\hline \multirow{2}{*}{ Áreas de Atuação } & \multicolumn{2}{|c}{$\%$} \\
\cline { 2 - 3 } & $\mathbf{1 9 9 0}$ & $\mathbf{1 9 9 5}$ \\
\hline Educação & 38,46 & 52,00 \\
Organização Popular & 50,77 & 50,00 \\
Saúde & 29,23 & 45,00 \\
Direitos Humanos & 26,15 & 39,00 \\
Emprego e renda & 21,54 & 38,00 \\
Planejamento participativo & 38,85 & 36,00 \\
Meio Ambiente & 20,00 & 32,00 \\
Uso da Terra & 32,31 & 30,00 \\
Arte e Cultura & 20,00 & 29,00 \\
Urbanização & 12,31 & 17,00 \\
Outras & 7,70 & 17,00 \\
\hline
\end{tabular}

Fonte: As ONGs e a realidade brasileira. Cadernos da ABONG, n. 6, jun. 1996.

OBS. A maioria das ONGs trabalha com mais de um tema.

Feito este inventário sobre as ONGs entrevistadas, e comparandoas com a realidade brasileira, em geral, e a da cidade do Recife, em particular, resta-nos responder a duas questões centrais das nossas preocupações: a) como as ONGs se organizam e que estratégias são utilizadas para mobilização de recursos?; b) em que sentido a crescente profissionalização e conseqüente disputa por recursos pode implicar em conflito entre as práticas desenvolvidas por essas instituições e o sentido original atribuído por seus fundadores e de qualquer modo ainda estruturador de suas identidades?

O discurso das ONGs, principalmente aquelas localizadas em países ao Sul do hemisfério, têm uma característica marcadamente libertária: a de combate a miséria, a exploração, a de denúncia e de porta-voz de populações oprimidas. As ONGs - muitas vezes definidas enquanto "ONGs cidadãs" - são um dos suportes mais importantes da sociedade civil, que se estruturam a partir de "uma rede de grupos e associações que se colocam entre, de um lado, famílias e relações face a face e, de outro, organizações estatais" (Cohen, 1999, p. 48); ou que se colocam "em defesa de setores da sociedade civil, excluídos ou à margem do processo de desenvolvimento socioeconômico, 
desempenhando um papel de mediação entre a sociedade propriamente dita, o mercado, e o Estado, através de parcerias em políticas públicas" (Gohn, 1995).

As práticas dessas ONGs, muito mais que simples prestadoras de serviços ou substitutas na execução das políticas públicas, significam um dos pilares importantes na estruturação de uma sociedade civil que, a partir de suas articulações ${ }^{31}$ - muitas vezes para além da esfera local - constróem espaços de poder, campos de inserção de segmentos sociais que normalmente não encontram lugar nos canais políticos tradicionais.

Este conteúdo libertário e agenciador de práticas políticas voltadas para a promoção dos excluídos parece ter sido a principal linha estruturadora da identidade das ONGs, conferindo significado de uma missão originariamente calcada na caridade, no altruísmo religioso do amor ao próximo, característico das ONGs primevas. Na América Latina - e especialmente no Brasil - isso começa a se tornar mais visível nos anos 60. E, aparentemente, ainda se apresenta como principal vetor na construção da identidade. Com efeito, perguntados sobre qual seria o papel de uma ONG, 23\% dos entrevistados afirmaram ser "contribuir para o exercício da cidadania"; $23 \%$ "promover o desenvolvimento da sociedade" e 13,1\% “propor e controlar ações públicas". Respostas que indiquem uma natureza mais diretamente ligada à assistência social ou de trabalhos caritativos localizar-se-iam na rubrica "produção de serviços sociais" $(31,1 \%)$, ou "outras respostas" $(9,8 \%)$.

A questão mais importante a ser ressaltada, quando falamos da missão da ONG - ou de sua identidade - diz respeito ao fato de que estaríamos assistindo a uma erosão dos princípios - ainda que amplamente aceitos ou divulgados - dessas instituições, ao constatarmos que suas práticas, de qualquer forma, colocariam conflitos relativamente graves entre o ser (ou o que se representa) e o agir (ou o que efetivamente se apresenta enquanto resultado de uma prática social concreta). Desta prática, algumas questões que se apresentam estratégicas para o bom desempenho - ou mesmo a sobrevivência - da instituição poderiam absolutamente apresentar-se incompatíveis com a representação identitária da ONG por parte de seus membros, e também por parte da sociedade. Duas questões sobressaem: a) o perfil do profissional da ONG; b) a maneira como a ONG arrecada os recursos necessários à execução de suas atividades. 


\section{Tabela 05 - Na opinião do entrevistado, o que deve fazer uma ONG?}

\begin{tabular}{l|r|c}
\hline & Contagem & $\begin{array}{c}\text { Percentual } \\
\text { de Respostas }\end{array}$ \\
\hline Produção de serviços sociais & 19 & 31,1 \\
Contribuir para o exercício da cidadania & 14 & 23,0 \\
Proposição e controle das ações públicas & 8 & 13,1 \\
Promoção para o desenvolvimento da sociedade & 14 & 23,0 \\
Outros & 6 & 9,8 \\
\hline Total & $\mathbf{6 1}$ & $\mathbf{1 0 0 , 0}$ \\
\hline
\end{tabular}

Fonte: Levantamento direto (2000).

O que tem caracterizado as ONGs, distinguindo-as das instituições localizadas no mercado ou do Estado, é o fato de serem estruturadas a partir da livre iniciativa de cidadãos, mobilizados para fazer face a estruturações de sociabilidade puramente instrumentais presentes no mercado ou no Estado ${ }^{32}$. O caráter de engajamento cívico ${ }^{33}$ seria um dos pilares da constituição dessas Instituições. ONGs são um dos ingredientes dos mais importantes na construção de uma sociedade civil forte, consequientemente um dos elementos fundamentais para a prática democrática; as associações voluntárias - incluindo-se aí as ONGs desta forma, "capacitam cidadãos para expressar seus interesses coletivos e solucionar problemas comunitários" (Lipsky, 1993, p. 3). Democracias fortalecidas seriam aquelas onde a sociedade civil se encontra "recheada" de associações voluntárias, vigor associativo que se reflete não somente no fortalecimento das instituições políticas (partidos e práticas da democracia representativa), mas também na promoção mais ampla de direitos. ${ }^{34}$

Como as ONGs trabalham o sentido original de sua missão diante do fato de terem de mobilizar recursos, cujas fontes muitas vezes exigem protocolos de operação relativamente incompatíveis com o discurso destas ONGs? É o caso, por exemplo, de uma ONG calcada em práticas fortemente denunciadoras da ação Estatal e, em algum momento, competir por recursos públicos. Ou o fato de, algumas vezes, as ONGs terem de competir por recursos adaptando-se à agenda da instituição financiadora. Se por um lado, dependem cada vez mais de fundos públicos, gerando desta forma menos recursos originários de 
contribuições privadas, por outro, o trabalho voluntário também é cada vez menos importante. A recorrência ao trabalho especializado, de dedicação integral é um fato entre as ONGs. É o que observa, por exemplo Lipsky (1993, p. 4), a propósito das ONGs norte-americanas, sobre os efeitos da crescente dependência de fundos públicos sobre a identidade destas instituições, colocando o fato de que "quando fundos públicos assumem um papel vital nos orçamentos das ONGs, é ingenuidade pensar que estas instituições não tem nenhum risco em colocar em perigo suas identidades".

Boa parte das ONGs pesquisada (55\% delas) conta com trabalho voluntário, mas, em relação ao número total das pessoas ocupadas, o trabalho voluntário é relativamente pouco importante. Com efeito, cerca de $40 \%$ das ONGs ocupam até $25 \%$ de pessoas trabalhando voluntariamente, ${ }^{35}$ e cerca da metade instituições pesquisadas empreguem somente até $50 \%$ das pessoas que tem aquela ocupação como principal. ${ }^{36}$ Constata-se, mesmo assim, uma certa precarização da força de trabalho, seja através do emprego temporário ou parcial, seja por embora menos importante do que normalmente se tem a impressão que seja - trabalho voluntário. A demanda por profissionalização, desta forma, se impõe.

Embora os dados não indiquem de forma definitiva, há claramente um sentimento por parte dos entrevistados de que um dos principais problemas enfrentados pelas ONGs diz respeito ao financiamento de suas ações. ${ }^{37}$ Problemas com financiamento remetem, de um lado, a processos de mobilização de recursos, como veremos mais adiante; por outro lado, dizem respeito a prováveis elementos desestabilizadores da estruturação identitária dessas instituições. Embora apenas 2,6\% dos entrevistados apontem como dificuldade relevante a falta de autonomia da entidade, temos outras pistas indicando uma relação complicada entre financiamento e sua missão original. Com efeito, se cruzarmos informações sobre avaliação das parcerias realizadas e processo de definição da agenda dos trabalhos feitos em parceria, verificamos uma associação negativa bastante alta $(-0,532)$ entre a nota atribuída pela ONG entrevistada e o fato de a agenda de trabalho ser definida pela entidade cooperante; relação que se torna positiva se a agenda for 
definida conjuntamente $(0,226)$ ou se for decidida apenas pela ONG entrevistada $(0,054) .{ }^{38} \mathrm{O}$ que significa que a cooperação entre ONGs e instituição financiadora tem uma tendência de ser avaliada negativamente quando as agendas são definidas unilateralmente pelo parceiro. Há, portanto, um claro desconforto entre o trabalho realizado e o que se pretende idealmente realizar. Referida situação - embora em determinado momento a sobrevivência da ONG dependa desta parceria - tende a ser provisória, dado o desconforto da relação. Há, destarte, uma forte relação positiva $(0,404)$ entre o tempo da duração da parceria e a definição da agenda estabelecida a partir da negociação entre os parceiros. ${ }^{39}$

Um ponto importante a ser considerado, mesmo admitindo que as ONGs na maioria dos casos negociam conjuntamente a parceria, é o fato de que os recursos utilizados pelas ONGs provêm em sua maior parte de fontes externas. ${ }^{40}$ Quer dizer, que há uma dependência - mesmo em se considerando que existe uma definição conjunta da agenda bastante significativa entre as ONGs e as instituições financiadoras.

As ONGs entrevistadas apresentam, como vimos, uma forte dependência de recursos externos - predominantemente oriundos da cooperação internacional, mas com presença importante de recursos públicos. ${ }^{41}$ Embora apresentando um razoável nível de satisfação dos trabalhos realizados com parceiros (nota média 4, em uma escala de 1 a 5), a satisfação com as parcerias não é uniforme, dependendo da forma como os recursos são negociados. Admitindo-se haver uma tendência crescente de financiamento públicos das ações das ONGs, e também considerando que o mecanismo de financiamento destas agências se dá a partir de editais - com, conseqüentemente, agenda previamente definida - há uma tendência de agravamento de questões relativas à estruturação identitária das ONGs, de um lado, e de autonomia, por outro, principalmente em relação ao Estado.

Temos, ainda, que considerar uma outra questão: dado o número relativamente importante de ONGs atuantes na Região Nordeste, e diante do fato de que se tem constatado escassez de recursos para financiamento de suas ações, seria razoável pensar que haveria uma competição 
crescente entre as ONGs por recursos. Já constatamos em outro lugar esta competição por recursos entre associações de moradores:

\begin{abstract}
... Mostramos que, independentemente do nível de associação existente entre o movimento e a comunidade que representa (a já tão estudada relação entre a liderança e sua base política), o sucesso da associação de moradores depende da satisfação da comunidade no que diz respeito às ações empreendidas. Ou seja, que a capacidade de uma associação de consolidar-se enquanto representante de uma comunidade está em relação direta com sua capacidade em mobilizar recursos. (Fontes, 1999, p. 221).
\end{abstract}

Não temos dados que possam confirmar esta hipótese, mas algumas informações apontam para esta direção, o que nos leva a considerar seriamente a sua validade. Há de se considerar, em primeiro lugar, que tanto o outdegree quanto o indegree $e^{42}$ relativos aos contatos entre as ONGs é bastante baixo (Tabela 6). As ONGs entrevistadas mantêm intenso relacionamento com diversos atores da sociedade civil, mas pouco contato com outras ONGs. Não existe, por exemplo, grande número de projetos desenvolvidos em parceria o que pode ser um indicador de que o que observamos entre as associações de moradores também se verifica entre as ONGs.

Tabela 6 - Indegree e Outdegree entre as ONGs entrevistadas

\begin{tabular}{l|c|c|c|c}
\hline \multirow{2}{*}{ Contatos com ONGs } & \multicolumn{2}{|c|}{ Outdegree } & \multicolumn{2}{c}{ Indegree } \\
\cline { 2 - 5 } & Num. & \% & Num. & \multicolumn{1}{c}{$\%$} \\
\hline Com nenhuma & 36 & 90,0 & 30 & 75,0 \\
\hline 01 & 02 & 5,0 & 09 & 22,5 \\
02 & 01 & 2,5 & 01 & 2,5 \\
07 & 01 & 2,5 & - & 00,0 \\
\hline Total & $\mathbf{4 0}$ & $\mathbf{1 0 0 , 0}$ & $\mathbf{4 0}$ & $\mathbf{1 0 0 , 0}$ \\
\hline
\end{tabular}

FONTE: Levantamento Direto.

Quando consideramos, entretanto, o Outdegree das ONGs em relação aos atores sociais de uma maneira geral, verificamos uma média 
de $8,325 .{ }^{43}$ E que há uma associação estatística ${ }^{44}$ entre o Outdegree e a média de movimentação financeira da ONG entrevistada, como nos mostra o gráfico abaixo. O que indica que, de certa forma, o sucesso da ONG em captar recursos é função do volume de contatos com atores da sociedade civil.

\section{OUTDEGREE E CAPACIDADE DE MOBILIZAR RECURSOS} Relação entreVolume de recursos captados e outdegree da entidade selecionada

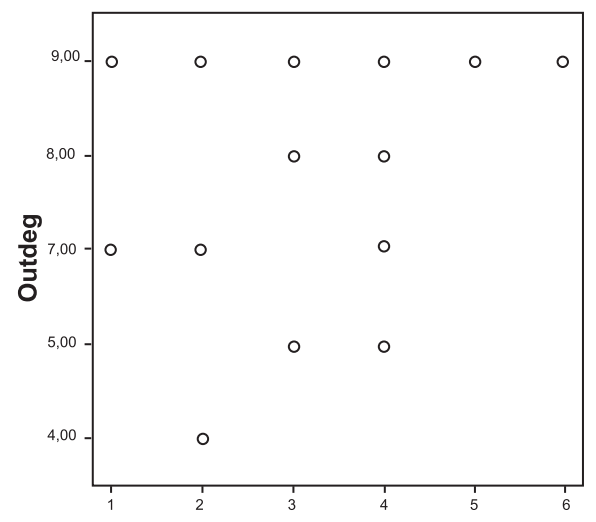

Média da movimentação financeira da entidade

\section{Conclusões}

Os estudos sobre o Terceiro Setor, como vimos, têm sido bastante freqüentes recentemente, visto a importância crescente deste atores sociais no cenário de sociedades em processos de contínuas e profundas mudanças. Tem-se questionado bastante sobre o papel das ONGs neste redesenho institucional por que têm passado nossas sociedades: redefinição do papel do Estado, os novos arranjos na esfera do trabalho, processos de intensos e perturbadores intercâmbios culturais, (des)localizando-se agora em um nível nunca antes visto, o de abrangência planetária; processos ainda não acabados que, como quaisquer outros relativos a mudanças deste grau de intensidade, provocam inquietações. Que significa o Terceiro Setor no redesenho das novas formas de solidariedade? Qual o real significado desta chamada "cidadania global", exercida através de práticas associativas 
deslocalizadas territorialmente? Como pensar em uma nova ordem mundial tendo em vista estes atores sem, entretanto, sobrevalorizar a sua importância?

A proposta deste artigo não é a de alçar vôos tão longos. Remete, antes, a questões bastante pontuais, relativas ao mecanismo de funcionamento destas ONGs, na sua atividade cotidiana e em relação com outros atores da sociedade civil. Esperamos ter contribuído de algum modo para o debate indicando questões bastante localizadas, é verdade, mas, principalmente, trabalhando com metodologias relativamente inovadoras na análise do Terceiro Setor. Referimo-nos, especificamente, à oportunidade em analisar esses atores a partir das relações que são estabelecidas entre eles, partindo do desenho de suas redes, e mostrar que a estruturação destas redes, de alguma forma, indica posições desses atores na estrutura social. Quer dizer, pretendemos indicar, a partir deste estudo empírico, não somente respostas a questões bastante específicas (sobre o processo de mobilização de recursos, sobre a dimensão dos vínculos sociais estabelecidos pelas ONGs), mas, principalmente, pistas metodológicas para a análise do processo associativo a partir do ponto de vista da análise das redes sociais.

\section{Notas}

1 A amostra "bola de neve" diz respeito a uma técnica estatística de extração de amostra não probabilística, construindo uma lista de nomes para entrevistas utilizando-se um conjunto inicial de nomes escolhidos a partir de informantes privilegiados. Esses nomes escolhidos são os entrevistados, que indicam um outro grupo de pessoas a entrevistar, e assim por diante, até o círculo se fechar (isto é, quando o número de pessoas indicadas e ainda não entrevistadas é pequeno). Este tipo de amostra é adequado para algumas pesquisas, especialmente aquelas utilizando-se do referencial teórico-metodológico das redes sociais. Sobre este assunto, consultar Kish (1995), Babbie (1995).

2 Pois, como afirma Scott (1997, p. 64), "the assumption of the snowball sampling method is that the connected segment of the network that forms the sample network is representative of all other segments of the network".

3 Estes índices serão explicados à medida de sua utilização neste artigo. Sobre os significados e os procedimentos metodológicos para sua extração, consultar Scott (1997) e Wasserman (1998). 
4 Na verdade, para o caso do mundo acadêmico brasileiro, a abordagem das redes sociais é bastante rara.

5 Muito mais, é certo, em visibilidade política que em recursos efetivamente alocados que, no caso das políticas sociais, continuam sendo oriundos majoritariamente do Setor Público. De qualquer forma, é inegável a crescente presença do Terceiro Setor nos processos de execução e fiscalização das políticas públicas.

6 Note-se, entretanto, que nem mesmo o mais radical dos chamados "neoliberais" subestimam o papel do Estado na promoção de políticas que aliviem a pobreza para os mais desafortunados. Cf. a resenha de Paul A Weissman do livro de Richard A. Epstein, A reconciling individual liberty with the Common Good (Reading, Mass. : Perseus Book, 1998): "Richard Epstein has made career of presenting cogent cases for radical libertarian positions... [meanwhile] The wholesale dismantling of government it calls for seems inconceivable in our era, even Epstein appears resigned at least to the continued existence of Social Security and Medicare". (Paul A. Weissman. Let be - Richard Epstein offers a systematic defense of laissez-faire economics. The New York Book Review, november, 1, 1998, p. 32).

7 Cf. Robert Castels e seus trabalhos recentes sobre exclusão social.

8 Mauss (2000); ver também a esse respeito, Godbout (1992).

9 Esta parte incorpora alguns trechos do artigo "Capital social e Terceiro Setor: sobre a estruturação das redes sociais em Associações Voluntárias”, publicado no Caderno do CRH, n. 30-31, p. 239-265, jan./dez. 1999.

10 Smith (1994), por exemplo, afirma que - com a contratação cada vez mais recorrente dos serviços das ONGs por Órgãos do governo - "o processo de desenvolvimento organizacional [das ONGs] tem acelerado".

11 Nos países subdesenvolvidos, as redes de solidariedade são o instrumento por excelência entre os pobres urbanos para aliviar situações de risco e incerteza. Sobre este assunto, consultar Panfichi (1997).

12 Outros, descritos por Godbout, se situam em casos de ações de dádiva onde os laços entre quem dá e quem recebe não são claramente estabelecidos. É o caso dos doadores de órgãos ou de sangue.

13 Esta é a crítica de Godbout às teorias da escolha racional, cujo caráter estritamente utilitarista impede visualizar certas ações baseadas na dádiva. Com efeito, conforme assinala Godbout, "o dom não obedece a nenhuma 
restrição, nem de autoridade, nem legal, nem mesmo racional, em função do cálculo. Ele obedece a um 'movimento da alma'” (p. 141).

14 Conforme afirma Burt (1998, p. 7), “capital social é uma qualidade criada entre pessoas enquanto capital humano é uma qualidade dos indivíduos”.

15 É a tese de diversos autores, que acreditam que as sociedades contemporâneas são mais funcionais ao surgimento de associações voluntárias.

16 Para o caso brasileiro, consultar Gohn (1995).

17 Consultar a este respeito W. Frits (1995) e Navarro (1994).

18 É o que, por exemplo, nos mostra Scherer-Warren (1996): “[as ONGs] em suas atuações políticas intercruzam-se em forma de relacionamento social, ora construído em torno de redes sociais primárias, resultante de identificações personalizadas, diretas, ora em torno de redes de movimentos, transnacionalizadas, efetuadas por meio de redes técnicas informatizadas".

19 Network exchange theory, no original.

20 Campo ocupacional, aqui, diz respeito ao ramo de atividades composto por uma atividade ocupacional específica, aqui pelas realizadas por ONGs. Não se trata, portanto, de uma categoria profissional, nem de um ramo de atividade econômica (visto que as ONGs são formadas por diversos ramos profissionais e de atividades).

$2155 \%$ das ONGS entrevistadas utilizam-se de algum tipo de trabalho voluntário, embora de forma relativamente secundária. A maior parte da mãode-obra empregada é remunerada e com nível elevado de escolaridade. Com efeito, $80 \%$ dos entrevistados tinham nível superior e destes, $15 \%$ com pósgraduação.

22 A literatura aponta uma tendência de diminuição de aporte de recursos originários da cooperação internacional. Os dados de que dispomos não nos permitem afirmar alguma coisa a respeito.

23 O tempo médio de fundação é de 14,5 anos.

24 Nas respostas sobre área de atuação da instituição, somente uma, "cidadania", poderia ser identificada como aquela representando ações de advocacy ou promoção da cidadania, típicas de ONGs atuando em países desenvolvidos.

25 Embora um número significativo destas instituições sejam confessionais.

26 Não temos informações sobre o volume de recursos financiados. 
27 Landim (1998) também apresenta um relato interessante do quadro do Terceiro Setor no Brasil.

28 Se considerarmos somente as ONGs, o número diminui consideravelmente. Entretanto, mesmo só computando as ONGs, de acordo com Clarke (1996, p. 1), o Brasil tem o maior número de ONGs entre os países em desenvolvimento, com 110.000 ONGs (definidas aqui enquanto organizações privadas, sem fins lucrativos, legalmente estabelecidas e imbuídas na produção de bens públicos).

29 Se considerarmos taxas geométricas de crescimento, temos $0,08 \%$ e 0,04\%, respectivamente para o Terceiro Setor e para o total da população econômicamente ativa no Brasil. A participação do Terceiro Setor em relação ao PEA cresceu de 1,4\%, em 1991, para 1,7\%, em 1995.

30 Este número apenas nos dá uma visão bastante imprecisa das ONGs atuando na Região. Dados da Receita Federal, do Ministério Público, das Prefeituras Municiais e dos Governos dos Estados nos dariam uma outra dimensão do fenômeno, embora ainda falha, visto que não há comunicação entre estes bancos de dados e suas metodologias são diversas. A dificuldade de acesso a estes bancos de dados, entretanto, não nos permitiu apresentar um quadro mais preciso.

31 Sobre as redes de ONGs e os processos de estruturação de práticas políticas globais, consultar Scherer-Warren (1996).

32 Refiro-me aqui especificamente à tese de Harbermas (1978) sobre a colonização do mundo da vida pela racionalidade instrumental.

33 Consultar, a este respeito, Powell (1998).

34 É conhecida a tese de Putnam sobre a relação entre vigor associativo e democracia. Consultar, a este respeito, Putnam (1978), Putnam (2000), Ottaway (2001).

35 Não temos informações sobre horas dedicadas por esta mão-de-obra voluntária.

36 As ONGs empregam em média 10,75 e 6,3 pessoas que têm naquela atividade a ocupação principal e secundária, respectivamente. É importante lembrar que $55 \%$ das ONGs entrevistadas empregam até 20 pessoas.

$3742,1 \%$ dos entrevistados afirmam que a escassez de recursos financeiros se constitui em uma das principais dificuldades enfrentadas por suas instituições. 
38 As ONGs entrevistadas citaram, em média, 1,4 instituições com quem mantêm algum tipo de atividade e que a agenda foi instituída a partir da própria ONG, 6 cujas agendas de trabalhos em comum foram definidas conjuntamente, e menos de uma cuja agenda de trabalho foi instituída a partir da instituição parceira.

39 Bem como uma relação negativa $(-0,328)$, quando a relação é definida exclusivamente pela entidade cooperante.

40 Apenas $12,5 \%$ das entrevistadas afirmaram não receber nenhum tipo de recurso de instituições com quem têm mantido algum tipo de cooperação.

41 As ONGs entrevistadas apontaram como fonte principal de recursos, cooperação internacional $(59,6 \%)$, recursos públicos - governos municipal, estadual e federal $(22,65 \%)$, pessoas físicas/empresas $(9,6 \%)$, outros $(7,7 \%)$.

42 Outdegree e indegree são definidos desta forma por Wasserman (1994, p. 125-126): "In a graph, the degree of a node is the number of nodes adjacent to it (equivalently, the number of lines incident with it). In a diagraph, a node can be either adjacent to or adjacent from another node, depending on the "direction" of the arc... Indegree is the number of arcs terminating at ni... Outdegree is the number of arcs originating with node ni".

43 O que é bastante alto, já que o Outdegree para este caso vai até 09 (quando a ONG entrevistada cita o máximo possível de parceiros previstos no questionário).

44 0,288, com nível de significância de 0,05.

\begin{abstract}
This article attempts to describe the process of strutuctarion of social networks in voluntary associations. Departing from an empirical survey in NGOs in the city of Recife, we investigate how social networks are built and the influence of their design in the action of NGOs. Firstly, we conclude that the relevance of the mission of the NGOs is not an essential element in mobilizing external ressources. To a great extent, the success of their action depends on the capacity they develop of atracting institutional ressources (from the State, the Church, International Cooperation, etc.) Second, the structuration of these networks makes possible the compairason of the relationship between the establishment of the agenda of these NGOs and the existence of conflict between this agenda and the purposes established at their original mission.
\end{abstract}


Résumé. L'article discute les mécanismes de structuration des réseaux sociaux en Associations Volontaires, à partir d'une recherche empirique des Organisations Non Gouvernementales de la ville de Recife. Cette perspective analytique nous permet observer quelques insights sur le fonctionnement des ONGs. D'abord, la capacité d'une ONGs à mobiliser des resources nécessaires à son activité n'est pas fonction exclusive de l'importance de son mission. Le succès de la mission depend de la disponibilisation de resources de ses parternaires (gouvernement, église, société civile, Cooperation Internationale, etc) et sa capacité peut être mesurée comparativemente aux autres institutions à partir du dessin de ces réseaux sociaux. Cela possibilite comparer le volume de capital social disponible. En suite, la structuration des réseaux associatifs nos permet de vérifier la dimension des liens institutionnels, et comme ses liens sont plus ou moins importants dans la détermination de l'agenda des ONGs en question. Et s'il y a un conflit entre cette détermination et la mission originele de l'ONG.

\section{Referências bibliográficas}

ABONG. As ONGs e a realidade brasileira. Cadernos da ABONG, v. 6, 1996.

BABBIE, Earl. The practice of social research. Belmont, CA : Wadsorth, 1995.

BANDIELD, Edward. The moral basis of a backward society. Chicago : The Free Press, The University of Chicago, 1958.

BURT, Ronald. The social structure of competition. In: NOHRIA, N; ECCLES, Robert G. Network organizations: structure, form and action. Cambridge: Harvard Univesity Press, 1992.

CLARKE, Gerald. Non-governamental organizations and politics in the developing world. Swansea : Centre for Development Studies, University of Wales, 1996.

COHEN, Jean L; ARATO, Andrew. Civil society and political theory. Cambridge, MA: The MIT Press, 1999.

COLEMAN, James. Foundations of social theory. Cambridge, MA: Harvard University Press, 1994.

DOUGLAS, James. Political theory of nonprofit organization. In: POWELL, Walter (Org.). The non profit sector: a research handbook. New Haven : Yale University Press, 1987. p 43-54. 
EPSTEIN, Richard. A reconciling individual liberty with the Common Good. Reading, Mass : Perseus Book, 1998.

FONTES, Breno A. S. M. Movimentos sociais: produção e reprodução do sentido. Recife : Ed. UFPE, 1999.

FRITS, W. NGOs in Latin América: past strategies, current dilemmas, future challenges. Oxford, England : INTRAC (The International NGO Training and Research Centre), 1995. (Occasional Paper Series, n. 8).

GODBOUT, Jacques. L'esprit du don. Paris : La Découverte, 1992.

GOHN, Maria da Glória. Cidades e ONGs: novas parcerias, novos atores. In: ENCONTRO NACIONAL DA ANPUR, 4. 1995. (Sessão temática: Agentes e Novas Formas de Interação Sócio-Espacial). Brasília, 1995.

GRANOVETTER, Mark. The strenght of weak ties: a network theory revisited. In: ALBANY CONFERENCE on contributor of networks analysis to structural sociology. 1981.

HABERMAS, Jürgen. Raison et légitimité: problèmes de legitimation dans le capitalisme avancé. Paris : Payot, 1978.

KISH, Leslie. Survey sampling. New York : Wiley Interscience, 1995.

KURTZ, Robert. Para além do Estado e mercado: autonomia de organizações comunitárias permite superar previsões da economia totalitária. Folha de S. Paulo, 3 dez. 1995, Caderno Mais, p. 15.

LANDIM, Leilah. The nonprofit sector in Brazil. In: ANHEIER, Helmut et al. Defining the nonprofit sector: a cross national analysis. Manchester : Manchester University Press. 1998.

LAVILLE, Jean Louis. L'économie solidaire: une perspective internationale. Paris : Desclée de Brower, 1994.

MARYKOUSKY, Barry et al. The seeds of weak power: an extension of network exchange theory. American Sociological Review, n. 58, p.197-209, 1993.

MAUSS, Marcel. The gift: the form and reason for exchange in archaic societies. London : W.W. Norton, 2000.

MELO, Marcus André. As ONGs no Brasil. Recife, 1997. (mimeogr).

NAVARRO, Juan Carlos (Ed.). Community organizations in Latin America. Washington DC : Inter-America Development Bank, 1997. 
OFFE, Klaus. Problemas estruturais do Estado capitalista. Rio de Janeiro : Tempo Brasileiro, 1975.

OTTAWAY, Marina. Strengthening civil society in other countries. The Chronicle of Higher Education, june 29, 2001.

PANFICHI, Aldo. Networks and identities among urban poor in Lima, Peru. In: LASA INTERNATIONAL CONGRESS, 1997, Guadalajara, Mexico. Panel POL41 (Networks and Political culture. Argentina, Brazil and Peru). 1997.

POWELL, Walter W; CLEMENS, Elisabeth S. Private action and the public good. New Haven : Yale University Press, 1998.

PUTNAM, Robert. Making democracy work: civic traditions in modern Italy. Princenton : Princenton University Press, 1993.

PUTNAM, Robert. Bowling alone: the collapse and revival of American community. New York : Simon and Schuster, 2000.

ROSANVALLON, Pierre. La crise de l’Etat Providence. Paris : Sueil, 1981. . La nouvelle question sociale. Paris: Sueil, 1995.

SCHERER-WARREN, Ilse. ONGs: os novos atores da "aldeia global". Paper apresentado no GT01 Cidadania, conflito e transformações urbanas, na XX Reunião Anual da ANPOCS, Caxambu, MG, out. 1996.

SCOTT, John. Social network analysis: a handbook. London : Sage, 1997.

SMITHT, Steven Rathgeb; LIPSKY, Michael. Nonoprofits for hire: the welfare state in the age of contracting. Cambridge, MA : Harvard University Press, 1994.

TOCQUEVILLE, Alexis de. A democracia na América. Belo Horizonte : Itatiaia, 1977.

WASSERMAN, Stanley; FAUST, Katherine. Social network analysis: methodos and applications. Cambridge, UK: Cambridge University Press, 1998.

WUTHNOW, Robert. Loose connections: joining together in America's fragmented communities. Cambridge, MA : Harvard University Press, 1998. 